\title{
Study on the TCM Healthy Pension Service Model in Sichuan Province
}

\author{
Yingyan Liu \\ School of Management \\ Chengdu University of Traditional Chinese Medicine \\ Chengdu, China
}

\author{
Hongying Wang* \\ School of Management \\ Chengdu University of Traditional Chinese Medicine \\ Chengdu, China \\ *Correspondence author
}

\begin{abstract}
The present study aimed to realize the effective integration of pension services and traditional Chinese medicine (TCM) resources in modern society, and effectively satisfied the growing diversified medical needs of the elderly. Through literature research and expert interview, this paper comprehensive analyzed the data of TCM pension model, and summarized the connotation and practice process of the TCM healthy pension service model in Sichuan province, found some challenging problems existing in pension model, including the subject of supervision was not clear, the support of funds and implementation of medical security system were insufficient, the demand level of the elderly population varied greatly and so on. Consequently, it is of great clinical significance for us to take some targeted suggestions, including perfecting the supervision system of Chinese medicine health pension, widening the channel of introducing and raising funds, improving the system of professional talents training and management, vigorously tapping the service needs of the elderly.
\end{abstract}

Keywords-Sichuan Province; TCM; Healthy care for the elderly; Pension model

\section{INTRODUCTION}

Developing the service for the elderly, which is a considerable part of the government's social security and people's livelihood undertakings. It is also a symbol of the construction of China's national social security system and the progress of social civilization. Under the background that the elderly population of China is becoming progressively severe, and the government gradually takes more seriously of the service for the aged, the elderly population of Sichuan presents the characteristics of large quantity and high proportion. In 2017 , the total population of the elderly aged 65 years and over in Sichuan ranked second in the country, after Shandong, and the proportion of the total population in Sichuan ranked third in the country, after Liaoning and Shandong [1]. Compared with 2010, the elderly population aged 60 years and over and their proportion in the permanent population, the elderly population aged 65 years and over and their proportion in the permanent population in Sichuan province are shown in Table I, it can be seen that the elderly population was developing speedily.

TABLE I

THE TOTAL NUMBER OF THE ELDERLY POPULATION IN SICHUAN DISTRIBUTION

\begin{tabular}{ccccc}
\hline & $\begin{array}{c}60 \text { years old and above(ten } \\
\text { thousand people) }\end{array}$ & Proportion(\%) & $\begin{array}{c}65 \text { years old and above(ten } \\
\text { thousand people) }\end{array}$ & Proportion(\%) \\
\hline 2010 & 1311 & 16.30 & 880 & 10.95 \\
2017 & 1751 & 21.09 & 1157 & 13.94 \\
\hline
\end{tabular}

At the same time, the elderly population in Sichuan has the characteristics of rapid growth, the aging level of the rural population obviously exceeded that of the urban population, the cumulative number of disabled and semi-disabled elderly people, and the continuing expansion of the elderly population in the future. In addition, the elderly mostly are vulnerable to physical failure, coexistence of multiple diseases and high incidence of chronic diseases. Therefore, the current pension problem not only include "provide care for the elderly", but also "provide medical treatment to the sick elderly". The traditional family and institutional pension model has much problems, such as separation of medical care and treatment. It cannot meet the health pension needs of the elderly population, which are enlarging nowadays.

\section{LiterATURE REVIEW}

\section{A. Related literature of Pension Model}

In 2005, Dong Guo introduced the concept of "combination of health care and continuous care" [2], in order to accomplish resource sharing and complementary advantages, which was through the combination of various ways between medical and pension institutions. Domestic scholars summarized the connotation of the integration of medical care and nursing into four aspects, including the service form, service content, service subject and service object. Scholars had also raised several major issues, such as the inadequate economic payment capacity of the elderly, the lack of policy support and the imbalance of regional development. Taixin He put forward measures that increase policy inclination and cultivate compound professionals [3]. Overseas countries have entered the aging process earlier, and the research mainly focused on the relationship between institutional model, service model, 
formal care and informal care, etc. Furthermore, the research results of diversified pension models in western developed countries mainly were concentrated on the contradiction between supply and demand, the typical pension models abroad and the influencing factors of pension model selection.

\section{B. Related literature of the TCM Healthy Pension Service Model}

TCM values the ideas of health preservation and disease prevention, which coincides with the concept of "great health" emphasized by modern society. Many scholars argued that we should utilizes the advantages of Chinese medicine in the pension in terms of "medicine treatment", " medicine care" and "prevention" [4], so as to effectively assimilate the pension with TCM. Li Sun have pointed out that there were some problems such as inconsistent service standards in pension institutions and imperfect incentive mechanism for professionals [5]. Ying An put forward some solutions, such as giving great policy guidance and actively expanding social resources [6]. Although some parts of China have carried out the pilot work of Chinese medicine health care for the elderly, the research and development in this area is quite slow, the time is comparatively short and the results are relatively small.

\section{CONNOTATION}

Healthy TCM pension has unique advantage and characteristic of the combination of medical and pension in China. It is under the guidance of TCM theory to regulate the human function of the elderly by using drugs and non-drug means and elements. TCM has good base and medical advantages in primary health services, consequently, it is the most satisfactory medical service item and an indispensable service content for the elderly, which can assist the elderly and prevent getting old. Additionally, in the plan of Sichuan province's implementation of the strategic outline for the TCM (2016-2030), it put forward to promote the development of TCM pension industry and encourage all kinds of TCM institutions at all levels for the elderly to establish a cooperative mechanism of medical and nursing integration.

Based on the integration of the pension and health care, the TCM healthy pension service model in Sichuan province is an innovative pension model that amalgamates medical treatment, prevention and health preservation, which introduces the concept of "pre-treatment of disease" and health care into families, communities and institutions. Compared with the traditional model, this model has some innovations in service object, service subject, service model and service content and the like [7].

The service objects include but are not limited to the elderly in health, sub-health and sub-clinical state, the elderly with disability and semi-disability such as chronic disease and rehabilitation period. Besides the traditional families, communities and all kinds of pension institutions, the service subjects also include TCM institutions and primary medical institutions. Its service contents include rudimentary life care, medical treatment, prevention, health care, rehabilitation and hospice care for the elderly.

\section{PRACTICE PROCESS}

At present, there are mainly five cities in Sichuan province that actively carry out the practice of the TCM healthy pension service model, such as Deyang, Guangyuan, Chengdu, Xichang and Neijiang. Here are five representative models.

\section{A. Setting up medical institutions in pension institutions}

Under this model, Chinese medicine departments are mostly set up for hospitals in institutions. Nanshan senior apartment in Deyang, has a second-class hospital with departments of internal and external medicine, Chinese medicine, E.N.T and medical laboratory. The organization has been selected as a designated medical insurance unit and actively provides high-quality services for residents. The Chinese medicine department's doctors in Jiazhou nursing home in Leshan, have rich clinical experience and can attract more elderly to come for treatment.

\section{B. Setting up pension institutions in medical institutions}

The Guangyuan hospital of TCM sets up the "Yikang Garden", which combines the characteristics of TCM with the medical care for the elderly. The staff of the "Yikang Garden" provide professional life and medical care for every elderly person, organize regularly lectures about health knowledge of TCM, and regularly carry out recreational activities, arming to complete "provide care for the elderly". Wolong Lake health treatment center of Zigong hospital of TCM mainly aims at sub-healthy people, providing services such as acupuncture, medicine bath, fumigation, hydrotherapy, oxygen therapy and so on. TCM therapy is used to treat "psychosomatic diseases". Psychotherapy and relaxation therapy are used to promote the body's function to reach the best state.

\section{Cooperation between pension institutions and TCM institutions}

Under the leadership of the government, Chengdu has innovated a new development model, which is named the "TCM + pension + community". Among them, the Chinese Medicine Museum of Qingyang district cooperates with Shuangxin Haojia nursing home, sets up Chinese medicine corner, provides Chinese medicine service for the elderly by the doctors of the Chinese Medicine Museum, and the hospital carries out the practice guidance of eight-section brocade in the nursing home every morning. Yikang elderly nursing home in Mianyang integrated medical institutions and pension institutions. It includes departments of Chinese medicine, integrated traditional Chinese and Western medicine, rehabilitation medicine, etc. This model combines TCM knowledge to provide services for patients with chronic diseases, long-term bedridden patients, elderly people who cannot take care of themselves and other patients who need long-term medical services.

\section{Social Capital Construction Institutions}

Yiyang Sansheng Pension Management Group has built the largest health care project in Xichang, creating a " the pattern of medical care"+ " the pattern of migrant" pension model, which is a typical example of the construction of TCM health pension institutions by social capital. Ethnic villages, scenic medical and nursing hospitals, TCM centers, apartments for the elderly, shopping centers and national cultural industrial parks 
has built in the base, and has formed the pension service projects that had the patterns of medical, migrant, experiential and chain-like.

\section{E. PPP model}

Neijiang and Yibin have formed PPP model. This model could not only effectively solve the financing problems, but also make use of the fruitful management experience of social capital to ensure efficiency of the use of funds in the pension service industry. Beginning in 2017, Dongxing district of Neijiang has building a TCM hospital which combines medical and health services with pension services. Maternal and child health hospital of Gongxian hospital of TCM in Yibin will also actively prepare for the comprehensive construction project of pension center.

\section{EXISTING DILEEMMAS}

\section{A. The subject of supervision is not clear}

Firstly, the overlapping of competent business departments, unclear boundaries of the responsibilities, supervision of TCM services by central administrative authorities at all levels, supervision of pension services by civil affairs departments at all levels, it is difficult for departments to break administrative barriers to achieve synergy [8]. The existing TCM healthy pension service model has not yet formed a monitoring and evaluation system, and there are no authoritative norms and standards for the services provided by various institutions and their modes, contents, prices, market competition, etc. It is challenging to evaluate the service work of various health care institutions of TCM. The quality of service provided by these institutions is uneven, the rights and interests of the elderly are difficult to be guaranteed.

\section{B. The support of funds and implementation of medical security system are insufficient}

There is a lack of security model aiming at the health characteristics of the elderly today. Most medical insurance funds are difficult to settle directly with the pension institutions. The model of combining medical care with medical treatment is in the process of promotion, some projects are in the vague zone of medical insurance reimbursement [9], which leads to the elderly unable to pay, and makes the health pension institutions of TCM at a disadvantage in the market competition. Relevant departments have not set up a special fund for the development of pension services. The expenditure of pension institutions cannot be linked to the health insurance fund, and the development of the institutions themselves is limited. Moreover, the establishment of Chinese medicine health care institutions for the elderly cannot be separated from the site, human resources, equipment and other elements, both software and hardware need sufficient funds to support. Many pension institutions are limited by funds and venues, so they cannot introduce relevant talents, provide special services of TCM, and develop healthy pension of TCM.

\section{Lack of professionals in TCM Healthy Service Model}

In 2017, the total number of caregivers in medical and nursing institutions in Sichuan province increased significantly compared with the previous years, conversely, it is still insufficient compared with the huge demand. There is a shortage of qualified professional service personnel, such as nutritionists, rehabilitation professionals and psychological consultants, especially those with TCM background. And with the influence of traditional concept, a small number of young people are willing to engage in pension services. With the advance of medical level and living standard, growingly elderly people need to be cared for, and the time of care is getting time-consuming. The number of employees in medical, nursing and rehabilitation institutions for the elderly in Sichuan is insufficient now, the quality of talents is not prominent, the ability is not formidable, and the stability is poor, which cannot meet the diversified needs of the growing elderly population.

\section{The demand level of the elderly population varies greatly}

Owing to the popularity rate of healthy pension of residents, especially rural residents, is stumpy, and the cost of TCM health pension institutions is higher than that of traditional family pension care. The occupancy rate of existing pension institutions is not high, and the policy support is not tough enough. The number of TCM health pension institutions in each city is not large, and the enthusiasm of various forces to establish TCM health pension institutions is not high. What's more, the existing Chinese medicine health pension institutions are mainly distributed in Chengdu, Mianyang and other places where the economy is more developed. The number of institutions in Suining and Neijiang, which rank the top among the elderly population in Sichuan province, nevertheless, is relatively small and cannot meet the local pension needs. Finally, the health care needs of the elderly at different income levels and demand levels are also different, and the service model is difficult to meet the various needs.

\section{SUGGESTIONS}

\section{A. Perfecting the supervision system of Chinese medicine health pension}

First of all, breaking the administrative barriers between "medical care" and " medical treatment". Relevant departments work together to establish a "four-in-one" supervision system with government supervision as the core, industry selfdiscipline as the link, internal control as the basis and social supervision as the supplement. To achieve the Chinese medicine health pension service system with home-based, community-based and medical institutions as the support. Secondly, the Ministry of Finance, the Ministry of Education, the Ministry of Justice, the Health Commission, the Aging Commission, the Social Work Association and the grassroots social service center for the elderly should jointly introduce the supervision system and implementation standards of Chinese medicine health pension service institutions as soon as possible. Formulate complete service standards, service management, post responsibilities, operation procedures, quality supervision and evaluation criteria, therefore, all agencies can follow the law in their service work. Finally, we should severely crack down on arbitrary charges, violations of regulations and vicious competition in the service work of institutions. Strengthen 
supervision, maintain rules and order, promote the healthy development of the industry.

\section{B. Widening the Channel of Introducing and Raising Funds}

Firstly, we should strengthen the reform of medical insurance, incorporate the rehabilitation and nursing programs of health pension institutions of TCM into the scope of medical insurance, and properly increase the pension insurance for urban and rural residents. Secondly, the proportion of medical insurance funds and accounts should be allocated reasonably, and resources should be inclined to the poor, the widows, the disabled, the mentally retarded and the disabled, consequently to alleviate their pressure on providing for the elderly. Thirdly, we could encourage social capital to enter the health pension projects of TCM by means of tax reduction, operation subsidy, mortgage loan discount and other policies, which will broaden the sources of funds for health pension services of TCM. Fourthly, we should actively guide charitable and other public welfare organizations to pay attention to the healthy pension of TCM, and strive for more social forces to support the hardware construction of pension service facilities, basic medical devices, entertainment facilities for the elderly.

\section{Perfecting the System of Professional Talents Training and Management}

First, we should reinforce the training of professional skills of employees in health and pension service institutions of TCM, regularly provide free skills training for employees, and establish training, assessment and incentive mechanisms to strengthen the education and management of service personnel in health and pension service institutions of TCM. Second, we could actively support and guide colleges and universities of TCM to set up such majors as nursing for the elderly, rehabilitation medicine of TCM, service for the elderly and management of nursing homes. Through training and directional commissioning, we should cultivate the shortage of professionals of nursing and managerial personnel of nursing institutions, and establish a healthy service training base for the elderly with TCM. Finally, we need to guide the society to enhance the understanding, attention and respect of the elderly nursing profession, rationally improve the treatment of the elderly nursing staff, and promote the stability of the elderly nursing team.

\section{Vigorously tapping the service needs of the elderly}

First of all, coordinate the service resources of medical, health system and civil affairs system of governments at all levels. According to the resources of community pension service information platform and population health information platform, comprehensively and systematically assess and grasp the health service needs of the elderly, making the existing service resources flow to high-demand areas. Furthermore, in terms of diet and sports, we should use various media to publicize the healthy pension support of TCM, constantly enhance the community's awareness of TCM services, and create a splendid social environment for the development of TCM. In order to meet the spiritual needs of the elderly, we should make our best to the advantages of talents in colleges and universities of TCM, organize college students and volunteers to enter pension institutions, carry out voluntary service activities such as reading newspapers, performing arts and so on. Lastly, according to different health status, diseases and their severity, we can provide the needs of elderly people with different health care services of TCM.

\section{CONCLUSIONS}

TCM with a history of thousands of years, is a plentiful practical experience and beneficial clinical effect systematic subject, Chinese medicine health care can better meet the needs of pension for the elderly. The TCM healthy pension service model in Sichuan province combines the elderly pension with medical resources in Sichuan, to achieve prevention before illness, maintenance before old age and improve the quality of life of the elderly. In the process of practice about this model, there are some problems in the supply of medical and health services and the demand of the elderly. The government and society should exert their respective strengths, existing resources should be rationally allocated and utilized, and shall improve the training system of professional talents in time, "provide care for the elderly, provide medical treatment to the sick elderly" maybe achieve in this way.

\section{REFERENCES}

[1] Sichuan Statistics Bureau. An Analysis of the Aging Population and Healthy Old-age Care in Sichuan Province[EB/OL],2018-6-29. (In Chinese)

[2] Dong Guo, Huiyou Li, Xuxian Li. Feasibility study on the combination of medical care and service for the elderly[J]. International Medicine and Health Report, 2005, 21: 45-46. (In Chinese)

[3] Taixin He. Research on the pension model based on the combination of medical and nursing $[\mathrm{D}]$. Yunnan University of Finance and Economics. 2017. (In Chinese)

[4] Fuchun SI, Xuejie SONG, Yan GAO. Probe into the Old-age Care Model of "Combination of Medical Care and Nursing" in Traditional Chinese Medicine[J]. TCM research,2016,29(8)1-3. (In Chinese)

[5] Li Sun. Discussion on the Model of Integrated Medical and Nursing Ward with Traditional Chinese Medicine in Community Health Service Center[D]. Chinese Academy of Traditional Chinese Medicine. 2016. (In Chinese)

[6] Ying An, Xiuqin Li. Analysis on the Healthy Nursing Mode of Traditional Chinese Medicine Combined with Medical Care[J]. Economic and trade practice,2017,(23): 180. (In Chinese)

[7] Min Tang, Haibo Wu. Research on the Service Model of Chinese Medical Healthy Old-age Care Based on the Combination of Medical Care and Nursing Care[J]. Health economics research,2017,(5):22-24. (In Chinese)

[8] Yingying Meng. Difficulties and Solutions to the Development of the "Medical-nursing Combination" Old-age Care Model in China[J]. Economic review,2016,(07):98-102. (In Chinese)

[9] Yanyi Wang, Jilong Gao. Structural Relations and Implementation Optimization of Medical-Maintenance Integration from the Perspective of Medical Insurance[J]. General practice in China,2017,20(3):278-282. (In Chinese) 